\title{
Bilateral segmental lung transplantation for children: Transplantation using split adult living-donor lower lobe
}

Takahiro Oto, MD, ${ }^{\mathrm{a}, \mathrm{b}}$ Yukiko Hikasa, MD, ${ }^{\mathrm{c}, \mathrm{d}}$ Akikazu Hagiyama, PT, ${ }^{\mathrm{e}}$ and Motomu Kobayashi, MD, Okayama, Hyogo, and Tokyo, Japan

\footnotetext{
From the ${ }^{\mathrm{a} T r a n s p}$ lant Center, Okayama University Hospital, Okayama; ${ }^{\mathrm{b}}$ Thoracic Surgery, Himeji Daiichi Hospital, Hyogo; ${ }^{\mathrm{C} A n e s t h e s i o l o g y}$ and Resuscitology, Okayama University Hospital, Okayama; ${ }^{\mathrm{d} A n e s t h e s i o l o g y}$, National Cancer Center, Tokyo; and ${ }^{\mathrm{e}}$ Physical Medicine and Rehabilitation, Okayama University Hospital, Okayama, Japan.

Disclosures: The authors reported no conflicts of interest.

The Journal policy requires editors and reviewers to disclose conflicts of interest and to decline handling or reviewing manuscripts for which they may have a conflict of interest. The editors and reviewers of this article have no conflicts of interest.

Received for publication June 3, 2020; revisions received June 3, 2020; accepted for publication June 17, 2020; available ahead of print June 21, 2020

Address for reprints: Takahiro Oto, MD, 2-5-1, Shikata-cho, Kita-ku, Okayama 700-8558, Japan (E-mail: yellowpeachoto@hotmail.com).

JTCVS Techniques 2020;3:311-4

2666-2507

Copyright (C) 2020 The Authors. Published by Elsevier Inc. on behalf of The American Association for Thoracic Surgery. This is an open access article under the CC BY-NC-ND license (http://creativecommons.org/licenses/bync-nd/4.0/).

https://doi.org/10.1016/j.xjtc.2020.06.022
}

Video clip is available online.

The shortage of pediatric brain-dead donors is a significant limiting factor for lung transplantations in small children. ${ }^{1,2}$ In Japan, living-donor lobar lung transplantation is a widely used alternative procedure, accounting for 33\% of lung transplantations in children. ${ }^{3}$ However, even lower lobe grafts might be too large to fit into a small child's chest cavity. $^{2,4,5}$ A bilateral segmental lung transplantation using an adult living-donor lower lobe was performed on 3 children who were considered unlikely to survive until a suitable pediatric brain-dead donor was allocated to them.

\section{CLINICAL SUMMARY}

Between August 2014 and December 2018, 3 children age 1,2 , and 4 years with idiopathic pulmonary fibrosis underwent bilateral segmental transplantation. All 3 children were mechanically ventilated with $80 \%$ to $100 \%$ oxygen concentration before transplantation (Figure 1). Characteristics of the children and their donors are shown listed in Table 1. The children's parents provided informed consent.

The donor operation commenced before the recipient operation. Splitting of the lower lobe into superior and basal segments was completed in vivo using electrocautery (Figure 2). The intersegmental veins were identified and preserved during division of the lung parenchyma (Video 1). The segmental grafts were reinflated, and hemostasis graft were secured.

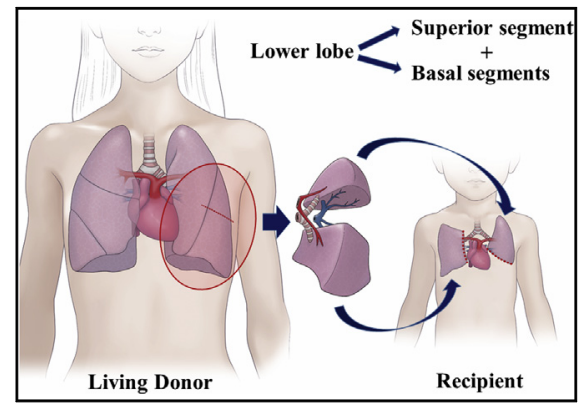

A wide communication can be seen between the right side of the aorta and the right lung.

\section{CENTRAL MESSAGE \\ In this case report, we had the chance to revisit syphilitic aortitis in the modern antibiotic era. Despite its rarity, cases of syphi- litic aortitis have been increas- ingly reported recently.}

See Commentaries on pages 315 and 317.

and sealing of air leaks from the dissected surface of the

The recipient operation began with hilum dissection and the initiation of cardiopulmonary bypass. The donor was then heparinized, and the bronchus and pulmonary vasculature was cut at the level of the lower lobe branches. Antegrade followed by retrograde pulmonary arterial flushing was performed on a back table. The donor graft was then divided into superior and basal segments by cutting the pulmonary artery, vein, and bronchus.

In each case, the superior and basal segments were transplanted into the recipient's left and right chest cavities, respectively. The superior segment was transplanted without changing its direction, and the segmental vein was anastomosed to the recipient's lower pulmonary vein. The basal segments were rotated 180 degrees horizontally and 90 degrees vertically, and then the segmental vein was attached to the recipient's upper pulmonary vein. Two patients required delayed chest closure due to size mismatch between the graft and the recipient's chest cavity (Table 1). The chest X-rays in acute and chronic phase are shown in Figure 1. Two patients recovered without requiring oxygen inhalation; however, 1 patient died due 
Case 1

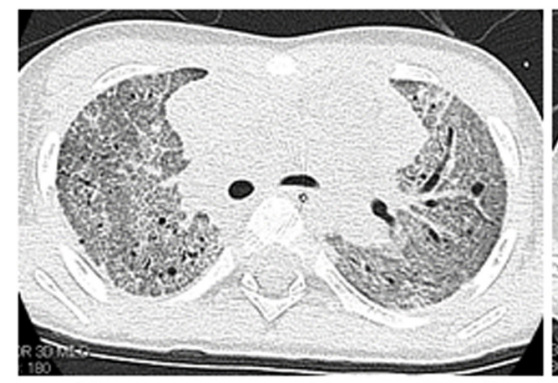

Pre transplant (Tx)

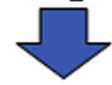

\section{-Acute phase-}

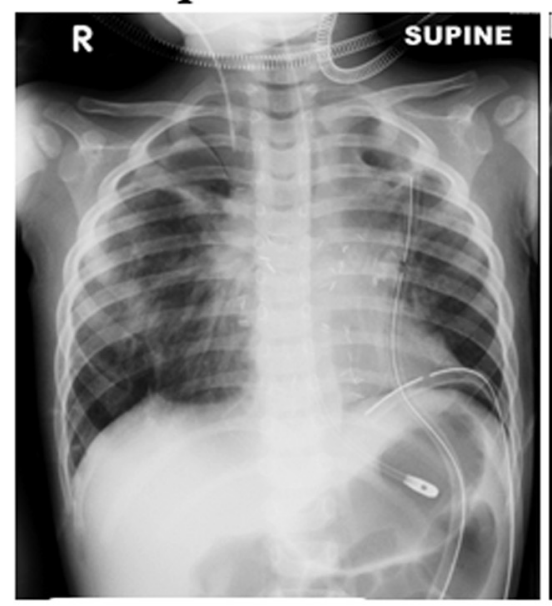

\section{4 days post $T x$}

-Chronic phase-

N.A.
Case 2

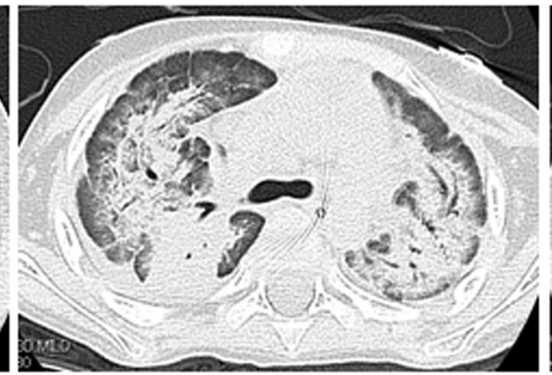

Pre transplant (Tx)
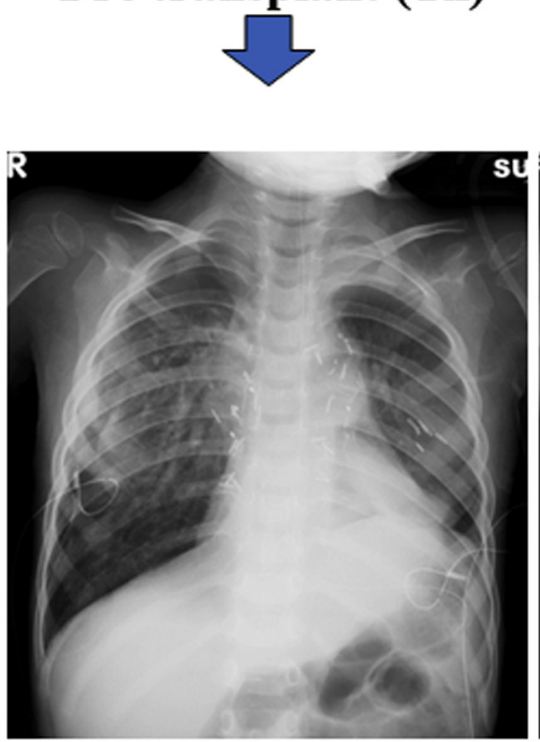

13 days post $T x$
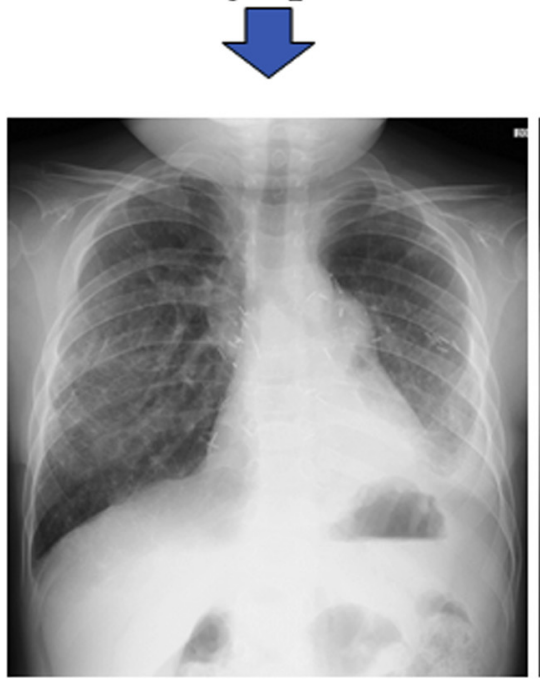

5 years post $T x$
Case 3

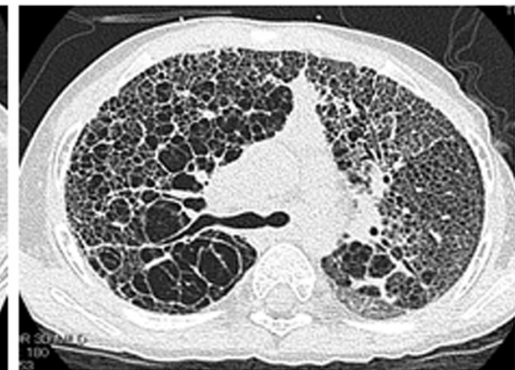

Pre transplant $(\mathrm{Tx})$
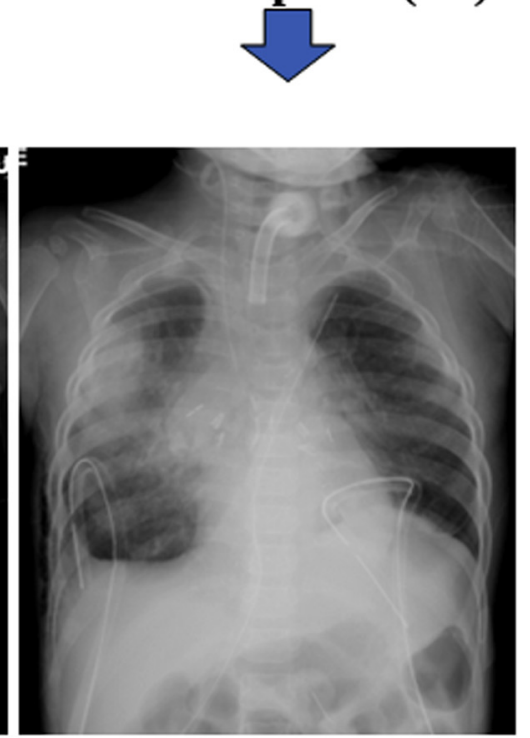

8 days post $T x$
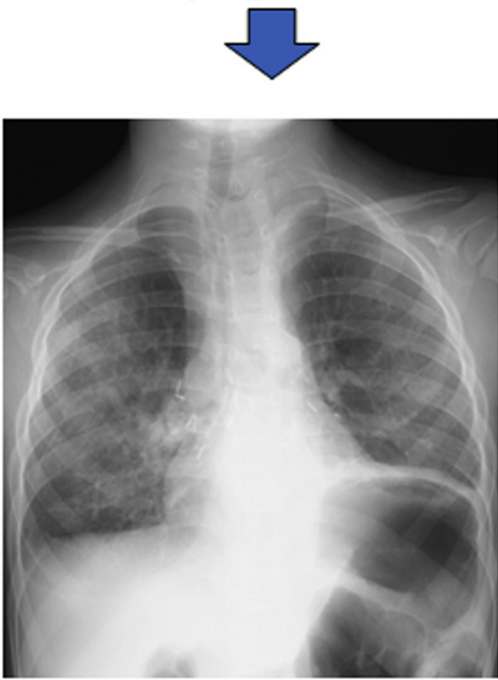

2 years post $T x$

FIGURE 1. Acute and chronic phases of computed tomography scan and chest X-ray. $T x$, Transplant; N.A., not applicable. 
TABLE 1. Characteristics of recipients and donors and outcomes of segmental transplant

\begin{tabular}{|c|c|c|c|}
\hline Characteristic & Patient 1 & Patient 2 & Patient 3 \\
\hline Recipient age, y & 1 & 2 & 4 \\
\hline Height/weight & $79 \mathrm{~cm} / 10 \mathrm{~kg}$ & $92 \mathrm{~cm} / 12 \mathrm{~kg}$ & $79 \mathrm{~cm} / 8.8 \mathrm{~kg}$ \\
\hline Preoperative pathology & NA & NSIP with DAD & UIP \\
\hline Genetic abnormality & SFTPC $^{173 T}$ hetero & No & No \\
\hline Donor & Mother & Mother & Father \\
\hline Donor genetic abnormality & No & NA & NA \\
\hline Donor graft & Right lower lobe & Left lower lobe & Right lower lobe \\
\hline Graft implanted & Right: basal/left: superior & Right: basal/left: superior & Right: basal/left: superior \\
\hline $\begin{array}{l}\text { Donor/recipient size matching } \\
\text { by CT volumetry, } \%\end{array}$ & 213.5 & 200.6 & 188.6 \\
\hline Immunosuppression & Tac + MMF + steroid & Tac + MMF + steroid & Tac + MMF + steroid \\
\hline Extubation, d & 4 & 13 & $8^{*}$ \\
\hline Follow-up period, mo & 3 & 68 & 29 \\
\hline Growth of patient, $\mathrm{cm}$ & NA & $105.8(+13.8)$ & $80.5(+1.5)$ \\
\hline Current status & Died & Alive & Alive \\
\hline Cause of death & Legionellosis & NA & NA \\
\hline
\end{tabular}

NA, Not applicable; NSIP, non-specific interstitial pneumonia; DAD, diffuse alveolar damage; UIP, usual interstitial pneumonia; SFTPC, surfactant protein C; $C T$, computed tomography; Tac, tacrolimus; $M M F$, mycophenolate mofetil. *Patient weaned from mechanical ventilation 8 days after transplantation and retained spontaneous breathing through a tracheostomy created during the preoperative period.

to legionellosis at 3 months after transplantation. The pulmonary arterial pressure of patient 2 gradually increased (right, 64/35/46/14 mm Hg; left, 77/38/52/16 mm Hg; systolic/diastolic/mean/mean pulmonary capillary wedge pressure, respectively) with a normal cardiac index (4.17), pulmonary vascular resistance $(8.82 \mathrm{~mm} \mathrm{Hg} / \mathrm{L} /$

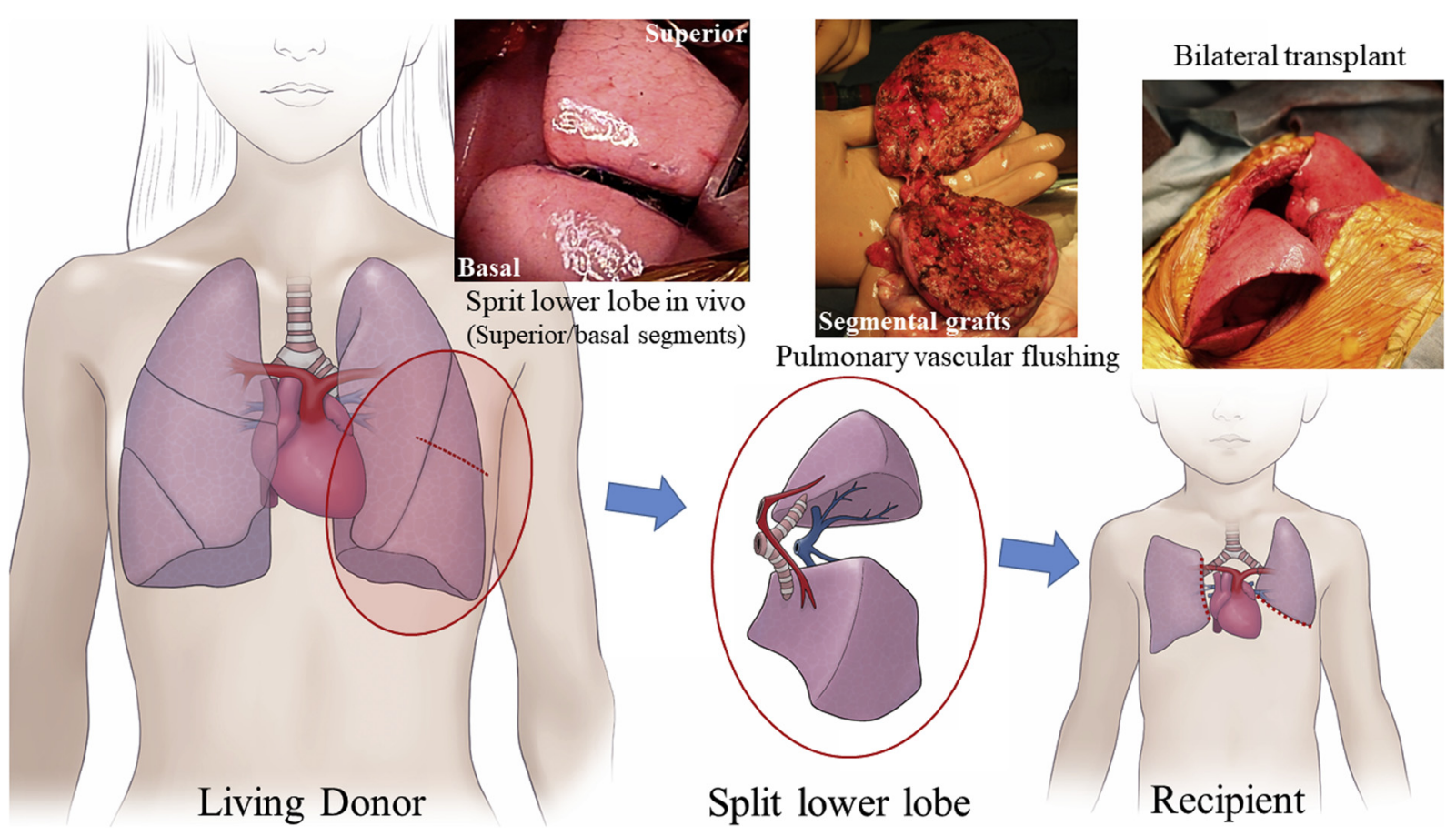

FIGURE 2. The donor's lower lobe was split into 2 segmental grafts in vivo, and graft preservation, including cold flushing, was performed ex vivo. The divided basal segments were rotated at 180 degrees vertically and 90 degrees horizontally and then placed into the recipient's right chest cavity. The recipient's left lower and right upper pulmonary veins were used for venous anastomosis. 


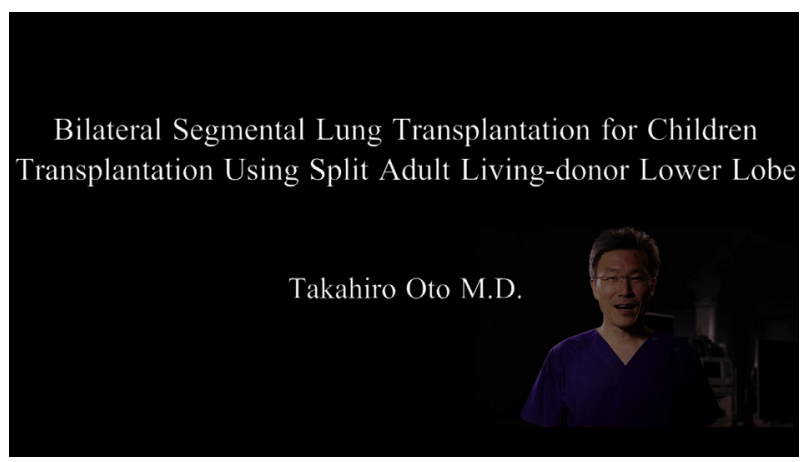

VIDEO 1. Donor and recipient operations. Video available at: https:// www.jtcvs.org/article/S2666-2507(20)30300-X/fulltext.

$\mathrm{min})$, left ventricular end-diastolic pressure $(15 \mathrm{~mm} \mathrm{Hg})$, and mean aortic pressure $(56 \mathrm{~mm} \mathrm{Hg}), 68$ months after transplantation. Therefore, the patient is now being considered for a retransplantation.

\section{DISCUSSION}

A previous report described living-donor middle lobe transplantation in toddlers, stating that the "middle lobe should have single arterial, venous, and bronchial branches; otherwise, the requirement for a patch repair might increase the potential surgical risks of the donor operation." ${ }^{4}$ In the 3 current cases, middle lobe transplants were considered; however, anatomic problems, including 2 middle lobe arteries, were discovered in 2 donors, and 2 middle lobe veins were discovered in 1 donor during the evaluation process. We consider a size mismatch between the pediatric recipient's chest cavity and the adult donor graft of $<250 \%$ to be acceptable in a bilateral transplantation ${ }^{2,4,5}$; however, the indication may change depending on the stiffness of the recipient's chest.

Although urgent transplantation using an adult living donor is possible, the patient is not likely to survive until a pediatric brain-dead donor is allocated. Bilateral transplantation is possible using a living-donor lower lobe.

The procedure does have some limitations. Retransplantation may be required in the near future as the recipient grows. In addition, a segmental graft carries a greater risk of bleeding and air leak compared with a whole lung or lobe.

Our experience with these cases demonstrates that bilateral segmental lung transplantation using a split adult living-donor lower lobe could bridge these children to suitable pediatric brain-dead transplants.

\section{References}

1. Sato M, Okada Y, Oto T, Minami M, Shiraishi T, Nagayasu T, et al. Registry of the Japanese Society of Lung and Heart-Lung Transplantation: official Japanese lung transplantation report, 2014. Gen Thorac Cardiovasc Surg. 2014;62:594-601.

2. Oto T. Living donor lobar lung transplantation. Kirklin J, ISHLT monograph series, Pediatric Lung Transplantation. Volume 7, Birmingham, AL: University of Alabama at Birmingham Printing; 2013:220-7.

3. The Japanese Society of Lung and Heart-Lung Transplantation. Registry Report of Japanese Lung Transplantation -2019. Jpn J Transplant. 2019; 54:105-10.

4. Oto T, Miyoshi K, Sugimoto S, Yamane M. Living related donor middle lobe lung transplant in a pediatric patient. J Thorac Cardiovasc Surg. 2015;149:42-4.

5. Oto T, Date H, Hayama M, Ando A, Shimizu N. Peripheral lung volume reduction improved early graft function in severe size mismatched living donor lobar lung transplantation. Transplant Proc. 2005;37:4515-21. 